\begin{tabular}{|c|c|c|c|c|}
\hline & $\begin{array}{l}\text { Jurnal Ilmiah } \\
\text { Mahasiswa } \\
\text { Kedokteran } \\
\text { Universitas } \\
\text { Airlangga }\end{array}$ & JUXTA: Jurnal IImiah Mahasiswa Kedokteran Universitas Airlangga & 2021 January, XII (01) \\
\hline
\end{tabular}

\title{
Sepsis: Antibiotic Resistances of Gram-Positive and Gram-Negative Bacterial in a Tertiary Care Hospital
}

\author{
Siti Nurul Jannah ${ }^{1}$, Muhammad Vitanata Arfijanto ${ }^{2 \star}$, Musofa Rusli ${ }^{2}$, Agung Dwi Wahyu Widodo $^{3}$
}

${ }^{1}$ Faculty of Medicine, Universitas Airlangga, Surabaya, Indonesia.

${ }^{2}$ Department of Internal Medicine, Faculty of Medicine, Universitas Airlangga/Dr. Soetomo General Hospital, Surabaya, Indonesia. ${ }^{3}$ Department of Clinical Microbiology, Universitas Airlangga/Dr. Soetomo General Hospital, Surabaya, Indonesia.

\section{A B S T R A C T}

Introduction: Sepsis is a systemic infection that causes multiorgan failure and death. The death rate that is caused by sepsis is increasing. This high value of death has a correlation with the resistance of antibiotics. However, increased antibiotic resistance is not balanced with new research about antibiotics. As a consequence, it causes difficulties in handling sepsis patients who need antibiotic 1-2 hours after diagnosis is enforced.

Methods: This was a descriptive study with case study design to analyze medical records of the patients, evaluating the pattern of bacterial resistance to antibiotic in 221 patients with sepsis with 240 blood isolates to identify.

Results: From 221 patients identified as sepsis, there were 97 male patients (43.9\%) and 124 female patients $(56.1 \%)$, mostly between $18-59$ years old $(63.8 \%)$, with the highest level in female $(54.8 \%)$ and elderly $(66.3 \%)$. The bacteria that caused the most sepsis were gram-positive. The most species in gram-positive are Staphylococcus haemolyticus (16.3\%) and Staphylococcus aureus (12.5\%), and the most species in gram-negative is Escheriichia coli (13.3\%). The most sensitive antibiotics in gram-positive bacteria were Piperacillin-Tazobactam (100\%), Daptomycin (99.2\%), and Clindamycin (99.2\%). The sensitive antibiotics in gramnegative bacteria were Amikacin (85.9\%), Cefoperazone (84.6\%), and PiperacillinTazobactam (84.1\%).

Conclusion: The most sensitive antibiotics in gram-positive bacteria were Piperacillin-Tazobactam, Daptomycin, and Clindamycin. The sensitive antibitics in gram-negative bacteria were Amikacin, Cefoperazone, and Piperacillin-Tazobactam.

\footnotetext{
*Correspondence: divtropin@yahoo.com

JUXTA: Jurnal IImiah Mahasiswa Kedokteran Universitas Airlangga p-ISSN: 1907-3623; e-ISSN: 2684-9453

DOI: 10.20473/juxta.V12I12021.29-37
}

Open access under Creative Commons Attribution-ShareAlike 4.0 International License (CC-BY-SA)

\section{ARTICLE INFO}

\section{Article history:}

Received 13 November 2020

Received in revised form 30

November 2020

Accepted 16 December 2020

\section{Keywords:}

Sepsis,

Antibiotic resistance,

Tertiary care hospital,

Staphylococcus haemolyticus,

Escheriichia coli. 


\section{Introduction}

Sepsis is defined as organ dysfunction that can be lifethreatening, caused by abnormal regulation of host response towards infection. The effect of misregulation resulted in imbalance of immune response, thus it could increase mortality. Organ dysfunction is represented as an acute change in total sequential organ failure assessment (SOFA) score $>2$ points caused by consequence of infection. Aside from SOFA score, patients with suspected infection predicted to perform long-term treatment in ICU or predicted to die in hospital could be identified quickly using Quick SOFA (qSOFA). ${ }^{1}$

There were 13 million people in the world who had sepsis every year and four million of them were dead because of sepsis. ${ }^{2}$ Every year, 750,000 cases of sepsis occur and become one of the top ten causes of death in the United States. ${ }^{3,4}$ In Germany, sepsis occurs as many as 60,000 people per year and is the third most common cause of death. ${ }^{5}$ In Indonesia, cases of sepsis are very high, it is proven in a study in a teaching hospital in Yogyakarta, there were 631 cases of sepsis in 2007 with a mortality rate around $48.96 \%{ }^{6}$

In Dr. Soetomo Hospital Surabaya, in 2011-2014 sepsis was the most diagnosed. From the data, it can be concluded that sepsis is one of the world's health burdens because not only developing countries have increased cases of sepsis but also developed countries. To overcome this, the system and intensive care therapy should constantly be updated. High mortality in sepsis patients was due to multiorgan failure and increasing levels of antibiotic resistance. The use of empirical antibiotics are needed to kill the causative organisms from sepsis and must begin within 1-2 hours after the diagnosis of sepsis is enforced. ${ }^{7}$ The choice of appropriate empirical antibiotics can reduce mortality rates in sepsis and the incompatibility of empirical antibiotics used will contribute to high mortality rate. ${ }^{8,9}$ Antibiotic resistance is influenced by the use of antibiotics, the facts that occur in Indonesian society, antibiotics are used freely even can be purchased without a prescription from the doctor. ${ }^{10}$ In addition, antibiotic resistance is associated with excess of used and abused of antibiotics. ${ }^{11,12}$ Inappropriate use of antibiotics will also make bacterial resistance and worsen the condition of sepsis patients, thus the crisis of antibiotic resistance is very influential in increasing the mortality rate of sepsis cases.

The types of bacteria that cause sepsis are varied, in general both gram-negative and gram-positive bacteria play a major role in causing sepsis. These bacteria produce various virulence factors which are able to escape from the body's immune defenses and able to spread to other organs, the toxins produced will trigger an irregular immune response. Nowadays, the organisms that cause sepsis, especially bacteria, have very rapid development by performing genetic mutations, thus the bacteria are able to tolerate antibiotics. ${ }^{13}$
It is proven by the discovery of Methicillin Resistant Staphylococcus aureus (MRSA), Vancomycin Resistant Enterococcus (VRE), Multi Drug Resistant (MDR) pseudomonas aeruginosa, imipenem resistant Acinetobacter baumannii, and third generation Cephalosporin-resistant Escherichia coli, and Klebsiella pneumonia, which are serious threats for public health. ${ }^{14}$ Unfortunately, the rapid development of bacteria has not been balanced with the development of new antibiotics. Currently, the discovery and development of antibiotics are decreasing while the resistance to antibiotics increases. This is shown by the discovery of new antibiotics in the past 11 years, only four new classes of antibiotics have been found. ${ }^{15}, 16$ Therefore, data on the patterns of antibiotic resistance in the bacteria that cause sepsis is needed for the antibiotics to be used rationally and wisely.

This study aimed to determine the pattern of antibiotic use and patterns of bacterial resistance in sepsis patients in Department of Internal Medicine Dr. Soetomo General Hospital Surabaya based on the results of existing culture in medical records of sepsis patients in January December 2017.

\section{Methods}

This was a descriptive study using cross-sectional design. The study population were sepsis patients in Department of Internal Medicine Dr. Soetomo General Hospital Surabaya from January to Desember 2017. The population studied were all patients with sepsis who were treated at inpatient room, Dr. Soetomo General Hospital Surabaya. The number of subjects were 240 blood isolates from 221 patients. Sampling technique used a total sampling method. Criteria for inclusion in this study were patients who were diagnosed with sepsis with positive blood culture (found bacteria in the blood isolate). The exclusion criteria in this study were patients who were diagnosed with sepsis without bacteria detection in the blood isolate. This study obtained data from clinical history and results of laboratory examination in medical records of patients with sepsis. The data were analyzed with descriptive statistics and presented in frequency distribution tables and diagrams. The statistical analysis used SPSS version 22.0.

\section{Results}

Data collection was done in Department of Clinical Microbiology Dr. Soetomo General Hospital Surabaya by taking blood specimen cultures data that was obtained from inpatient rooms in Department of Internal Medicine Dr. Soetomo General Hospital Surabaya from January to December 2017. From the data collection, there were 1,371 blood specimens with $385(28.1 \%)$ isolates with positive culture. Then the medical record data of the patients was taken to Department of Internal Medicine Dr. Soetomo General Hospital Surabaya to find total patients diagnosed 
with sepsis. After entering the inclusion and exclusion criteria, out of 385 blood isolates with positive culture results, there were $240(62.3 \%)$ isolates which were diagnosed with sepsis in 221 patients included in the study.

Characteristics of sepsis patients

Table 1. Primary diagnostic of sepsis patients.

Aplastic Anemia
Anemia hemolisis
AML (Acute Myeloid Leukemia)
ARF (Acute Renal Failure)
CRF (Chronic Renal Failure)
CKD (Chronic Kidney Disease)

Cushing Syndrome Unspecified

Chemotherapy Session for Neoplasm

Cholangitis

Cirrhosis of Liver

CAP (Community Acquired Pneumonia)

Cerebral Infraction

Cellulitis

Cervical Disease Disosder with Myelopathy

Bullous Erythema Multiforme

DMNID R (Diabetes Mellitus Non Insulin Dependent) + Renal Complication

DMNID M (Diabetes Mellitus Non Insulin Dependent) + Multiple Complication

DMNID P (Diabetes Mellitus Non Insulin Dependent) + Peripheral Circulatory Complication

DMNID C (Diabetes Mellitus Non Insulin Dependent) + Coma

DMNID TC (Diabetes Mellitus Non Insulin Dependent) without Complication

Diabetes Mellitus type 2

Diabetes Mellitus type $2+$ Coma

Unspecified Diabetes Mellitus + Ketoasidosis

Unspecified Diabetes Mellitus + Renal Complication

DHF (Dengue Hemorrhagic Fever)

Encephalopathy

Erythematous Condition

$\mathrm{CML}$

GI Hemorrhage

HIV + Candidiasis

NHL (Non Hodgkins Lymphoma)

Hypokalaemia

Gastric Ulcer

Gastroenteritis \& Colitis

Hypertensive Heart \& Renal Disease

Hypertensive Renal Disease

SSS Hypertensive

Malignant Neoplasia of cervix uteri

Malignant Neoplasia of breast

Frequency (blood isolate) 
Malignant Neoplasia of Intrahepatic Bile Duct Carcinoma

Malignant Neoplasia of Kidney

NEC

Other Obs \& Reflux Uropathy

Obstruction bile duct

Pneumoniae

Prolonged Hypoglikemia

Pyogenic Arthritis

Pulmonary Edema

SH Child B

Shock Sepsis

Sepsis

SLE

Toxic Epidermal Necrolysis

Thyroid Crisis or Stroma

Unspecified Adverse Effect of Drug or Medicament

UTI (Urinary Tract Infection)

Leptospirosis

Septicaemia

Amyloides

Anaemia

DMNID (Diabetes Mellitus Non Insulin Dependent) + Other Spesific Complication

Hepatic Failure

TB Paru

Congestive Heart Failure \& Renal Failure

Malignant Neoplasm of Nasopharynx

Benign Neoplasm, Liver

Total

Source: research data, processed

Table 1 shows that the primary diagnostic of sepsis patients was caused mostly by DMNID M (Diabetes Mellitus Non Insulin Dependent) with Multiple Complication.

Table 2. Characteristics of sepsis patients

\begin{tabular}{|c|c|c|c|c|c|}
\hline \multirow{2}{*}{\multicolumn{2}{|c|}{ Characteristics }} & \multirow{2}{*}{$\begin{array}{l}\text { Total Patients } \\
\text { (\%) }\end{array}$} & \multicolumn{3}{|c|}{ Results } \\
\hline & & & \multirow{2}{*}{$\begin{array}{l}\text { Recovered } \\
(\%)\end{array}$} & \multirow{2}{*}{$\begin{array}{l}\text { Died (\%) } \\
45(46.4)\end{array}$} & \multirow{2}{*}{$\begin{array}{l}\begin{array}{l}\text { Not } \\
\text { Recovered } \\
\text { (\%) }\end{array} \\
10(10.3)\end{array}$} \\
\hline \multirow{2}{*}{ Sex } & Male & $97(43.9)$ & & & \\
\hline & Female & $124(56.1)$ & $49(39.5)$ & $68(54.8)$ & $7(5.7)$ \\
\hline \multirow{2}{*}{$\begin{array}{l}\text { Age } \\
\text { (Years } \\
\text { old) }\end{array}$} & Adult (18-59) & $141(63.8)$ & 67 (47.5) & $60(42.6)$ & $14(9.9)$ \\
\hline & Elderly $(\geq 60)$ & $80(36.2)$ & $24(30)$ & $53(66.3)$ & $3(3.7)$ \\
\hline
\end{tabular}

Source: research data, processed

Table 2 shows that the patients were mostly female with 124 patients $(56.1 \%)$. Whereas from the age, the majority was in the adult age group (18-59 years old) with 141 patients $(63.8 \%)$. The highest mortality rate occurred in female $(54.8 \%)$ and elderly $(66.3 \%)$.
Distribution of gram-positive and gram-negative in sepsis patients

Table 3. Distribution of gram-positive and gram-negative. 


\begin{tabular}{|c|c|c|c|c|}
\hline \multirow{2}{*}{$\begin{array}{l}\text { Type of } \\
\text { Bacteria }\end{array}$} & \multicolumn{3}{|c|}{ Form of Bacteria } & \multirow{2}{*}{$\begin{array}{c}\text { Total } \\
(\%)\end{array}$} \\
\hline & $\begin{array}{c}\text { Coccus } \\
(\%)\end{array}$ & $\begin{array}{c}\text { Basil } \\
\text { (\%) }\end{array}$ & $\begin{array}{c}\text { Cocobasil } \\
(\%)\end{array}$ & \\
\hline $\begin{array}{l}\text { Gram- } \\
\text { positive }\end{array}$ & $\begin{array}{l}161 \\
(92.5)\end{array}$ & $\begin{array}{l}12 \\
(6.9)\end{array}$ & $1(0.6)$ & $\begin{array}{l}174 \\
(72.5)\end{array}$ \\
\hline $\begin{array}{l}\text { Gram- } \\
\text { negative }\end{array}$ & 0 & $\begin{array}{l}66 \\
(100)\end{array}$ & 0 & $\begin{array}{l}66 \\
(27.5)\end{array}$ \\
\hline
\end{tabular}

Table 3 shows that the most bacteria in the blood specimen which caused sepsis in patients with positive culture was gram-positive with 174 isolates (72.5\%) and the most form of bacteria in gram-positive was coccus with 161 isolates $(92.5 \%)$.

Source: research data, processed

\section{The pattern of antibiotic resistances to gram-positive bacteria in sepsis patients}

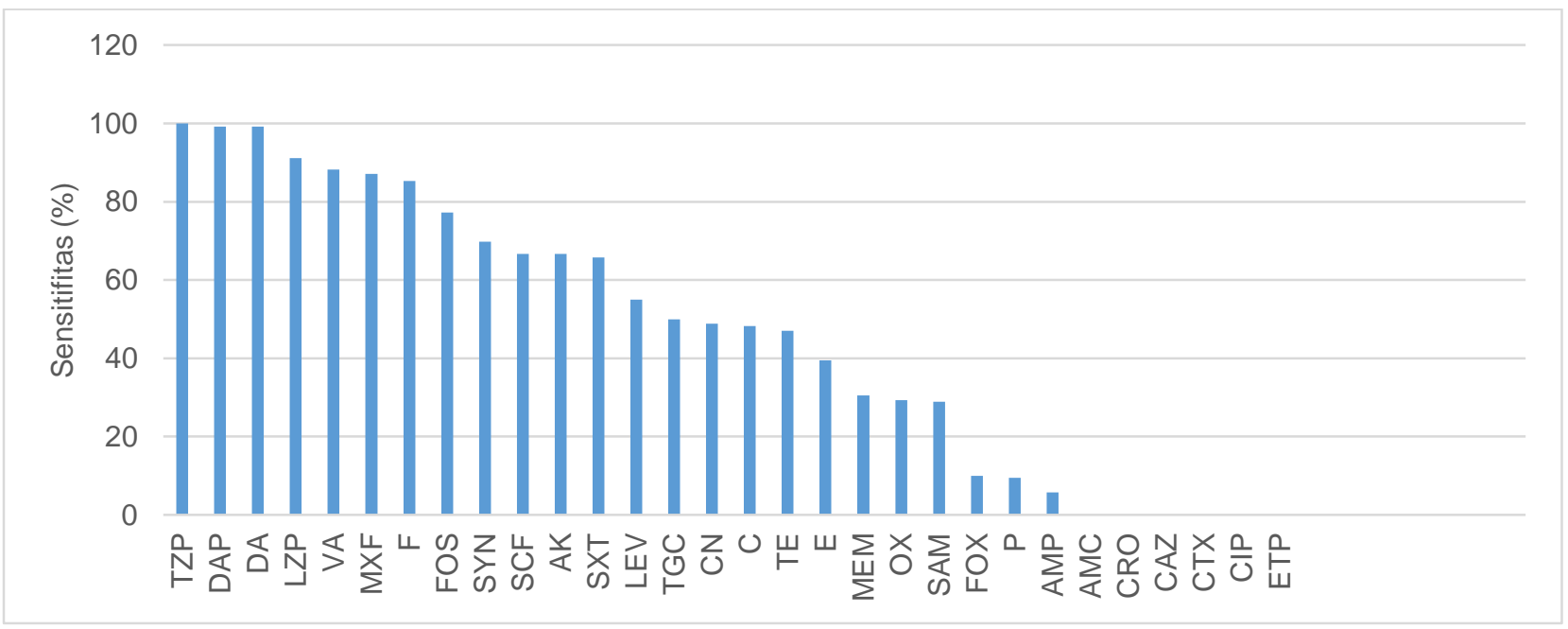

Figure 1. Antibiotic resistance in gram-positive bacteria.

In sepsis patients caused by gram-positive bacteria, antibiotics that were sensitive $\geq 50 \%$ were PiperacillinTazobactam (100\%), Daptomycin (99.2\%), Clindamycin (99.2\%), Linezolid (91.1\%), Vancomycin (88.2\%), Moxifloxacin (87.1\%), Nitrofurantoin (85.3\%), Fosfomycin (77.2\%), Quinopristin-Dalfopristin (69.8\%), Cefoperazone $(66.7 \%)$, Amikacin (66.7\%), Trimethoprim-
Sulfamethoxazole (65.8\%), Levofloxacin (55\%), and Tigecyclin (50\%). While antibiotics which were $100 \%$ resistant were Amoxicillin, Ceftriaxone, Ceftazidime, Cefotaxime, Ciprofloxacin, and Ertapenem, followed by Ampicillin (94.2\%), Penicillin (90.5\%), Cefoxitin (90\%), Ampicillin-Sulbactam (71.1\%), Oxacillin (70\%), and Meropenem (69.5\%).

\section{The pattern of antibiotic resistances to gram-negative bacteria in sepsis patients}

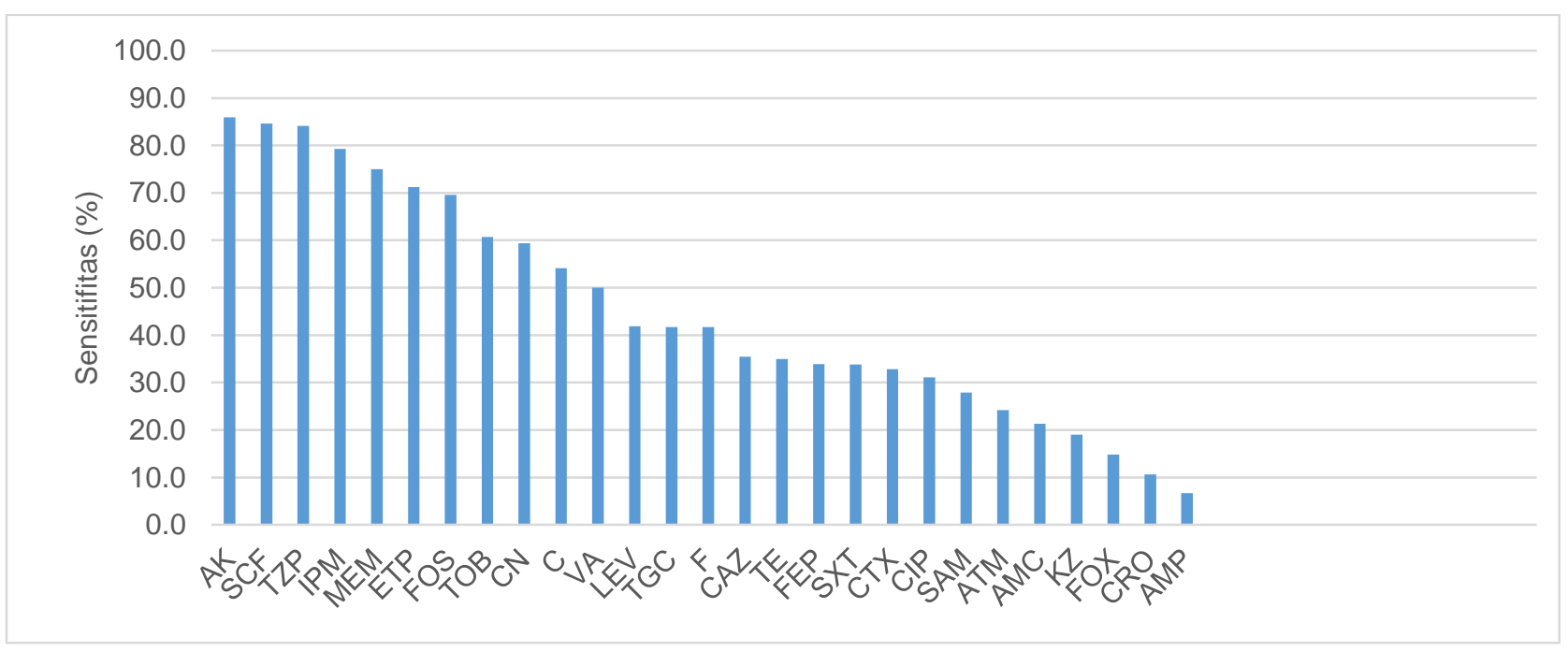

Figure 2. Antibiotic resistance in gram-negative bacteria.

In sepsis patients caused by gram-negative bacteria, antibiotics that were still sensitive $>50 \%$ were Amikacin (85.9\%), Cefoperazone (84.6\%), Piperacillin-Tazobactam
(84.1\%), Imipenem (79.3\%), Meropenem (75\%), Ertapenem (71.2\%), Fosfomycin (69.6\%), Tobramycin (60.7\%), Gentamycin (59.4\%), Chloramphenicol (54.1\%), 
and Vancomycin $(50 \%)$. While antibiotics which were $>50 \%$ resistant were Ampicillin (93.3\%), Ceftriazone $(89.4 \%)$, Cefoxitin (85.2\%), Cefazolin (81\%), Amoxicillin (78.7\%), Aztreonam (75 , 8\%), Ampicillin-Sulbactam (72.1\%), Ciprofloxacin (68.9\%), Cefotaxime (67.2\%), Trimethoprim-Sulfamethoxazole (66.2\%), Cefepime (66.1\%), Tetracyclin (65\%), Ceftazidime (64.5\%), Nitrofurantoin (58.3\%), Tigecyclin (58.3\%), and Levofloxacin (58.1\%).

\section{Discussion}

\section{Characteristics of sepsis patients}

Most sepsis patients were female (56.1\%), this is similar to some previous studies. ${ }^{6,17}$ The number of female patients diagnosed with sepsis was higher than male patients. ${ }^{18}$ Nevertheless, other previous studies showed the most sepsis patients were male. ${ }^{19}, 20$ This result indicated that female patients increased in sepsis because in some previous studies the highest incidence of sepsis patients were male, but now the incidence in female patients began to increase. This condition has to be prevented by giving more attention to health, especially in cases of infection in female, because they are more often exposed to infections than male, mainly during labor or postpartum that can cause death. ${ }^{21}$

In this study, adult patients became the highest number of sepsis patients (63.8\%). Therefore, age is one of the important factors that needs to be considered, especially in adults, because they are in productive age and able to work and produce something. Thus, prevention and comprehensive treatment are needed early in cases of infection not to fall into the state of sepsis.

The mortality rate in sepsis patients showed the highest results in elderly patients $(66.3 \%)$. This is similar with a previous study. ${ }^{22}$ In addition, the incidence of severe sepsis was increased in elderly patients, thus it increased mortality in elderly patients. ${ }^{23}$ Elderly sepsis patients had a mortality rate 2.3 times higher. ${ }^{24}$ Mortality influenced by the immune response in elderly began to decline. ${ }^{25}$ The immune response will affect the severity of an illness and help the healing process of the disease. If the immune response goes down, the patient will be difficult to cure, therefore the severity will increase and the mortality also increases. In addition, elderly patients often have chronic diseases, thus the treatment is taken in long term and they have to stay in the hospital in long term too, this also affects mortality in the elderly. ${ }^{19}$

Incompatibility of empirical antibiotic therapy will cause a high mortality rate in sepsis patients. ${ }^{9}$ Patients who receive appropriate initial antibiotic therapy will have a lower mortality rate. ${ }^{26}$ Therefore, it is suggested to prevent high mortality rate in sepsis patients by using antibiotics wisely and using appropriate empirical antibiotics.

\section{Distribution of gram-positive and gram-negative in sepsis patients}

The organism that caused sepsis has changed every year. Based on a study in the United States, it was revealed that from 1979 to 1987 the dominant organism causing sepsis were gram-negative bacteria, but after 1987 it changed to the dominant gram-positive bacteria and other organisms. ${ }^{19}$ In this study, it can be seen that the most bacteria that caused sepsis was gram-positive (72.5\%) with the most form was coccus $(92.5 \%)$. These results are similar with a previous study that stated the most common organism that caused sepsis was gram-positive cocci. ${ }^{6}$ In addition, this result was also found in some previous studies that stated the most causative organisms were gram-positive bacteria. ${ }^{6,20,27}$ Gram-positive bacteria as a cause of sepsis increases over time. ${ }^{20}$ This increase is probably due to the use of invasive procedures in the treatment and also increased hospital-acquired infections. ${ }^{28}$

\section{The pattern of antibiotic resistances to gram-positive bacteria in sepsis patients}

The results of this study showed that gram-positive bacteria caused sepsis with $\geq 50 \%$ antibiotic sensitivity, the 14 antibiotics were Piperacillin-Tazobactam, Daptomycin, Clindamycin, Linezolid, Vancomycin, Moxifloxacin, Nitrofurantoin, Fosfomycin, Quinopristin-Dalfopristin, Cefoperazone, Amikacin, TrimethoprimSulfamethoxazole, Levofloxacin, and Tigecyclin. Meanwhile 16 antibiotics with a resistance level $\geq 50 \%$ were Amoxicillin, Ceftriaxone, Ceftazidime, Cefotaxime, Ciprofloxacin, Ertapenem, Ampicillin, Penicillin, Cefoxitin, Ampicillin-Sulbactam, Oxacillin, Gentamycin. Chloramphenicol, Tetracyclin, Erytromycin, and Meropenem.

In a previous study, it showed various kinds of results. Amoxicillin, Ceftriaxone, Chloramenicol, Erytromycin, Vancomycin, and Ciprofloxacin had high sensitivity, but was highly resistant to penicillin and ampicillin. ${ }^{18}$ Nitrofurantoin, Vancomycin, and Chlorampenicol had high sensitivity. ${ }^{29}$

The use of antibiotics is strongly influenced by the spectrum of activity bacteria. ${ }^{30}$ Antibiotics that include broad spectrum in this study were Ampicillin, Amoxicillin, Cefoxitin, Ceftriaxone, Ceftazidime, Cefotaxime, Cefoperazone, Meropenem, Ertapenem, Fosfomycin, Chloramphenicol, Tetracyclin, Tigecyclin, Levofloxacin, Ciprofloxacin, Nitrofurantoin, Ampicillin-Sulbactam, and Trimethoprim-Sulfamethoxazole. From 18 broad spectrum antibiotics, only 6 that were still sensitive, namely Cefoperazone, Fosfomycin, Tigecyclin, Levofloxacin, Nitrofurantoin, and Trimethoprim-Sulfamethoxazole. Antibiotic that was included in the moderate spectrum in this study was Erytromycin. In this study, Erytromycin had high resistance. Meanwhile, narrow spectrum in this study 
were Penicillin, Oxacillin, Vancomycin, Daptomycin, Clindamycin, Quinopristin-Dalfopristin, Linezolid, Gentamycin, Amikacin, and Moxifloxacin. In this study, from 10 narrow antibiotics, 7 were still sensitive, namely Vancomycin, Daptomycin, Clindamycin, QuinopristinDalfopristin, Linezolid, Amikacin, and Moxifloxacin.

In this study, the three most sensitive antibiotics were Piperacillin-Tazobactam, Daptomycin, and Clindamycin. Antibiotics Piperacillin-Tazobactam is a combination of Penicillin- $\beta$-lactamase inhibitors used in empirical therapy for infections caused by a broad spectrum of potential pathogens in immunodeficient and immunocompetent patients, as well as management of infections in a mixture of aerobic and anaerobic bacteria. ${ }^{31}$ These antibiotics had a high sensitivity because it is a combination therapy. Daptomycin is a new antibiotic that was approved by FDA in $2003 .{ }^{16}$ These antibiotics spectrum of activity was the same as Vancomycin for gram-positive bacteria, but its activity was faster than Vancomycin, thus it can be used for indications of Staphylococcus aureus and Vancomycin resistant enterococcus. ${ }^{31}$ Therefore, the level of antibiotic resistance is low. The action mechanism of Clindamycin is done by inhibiting bacterial protein synthesis. Streptococcus, Staphylococcus, and Pneumococcus bacteria can be inhibited by Clindamycin. ${ }^{31}$

In this study, there were 6 antibiotics that experienced full resistance (100\%), namely Amoxicillin, Ceftriaxone, Ceftazidime, Cefotaxime, Ertapenem, and Ciprofloxacin. All of these are $\beta$-lactam antibiotics because they have a resistance mechanism by producing $\beta$-lactamase which is able to open $\beta$-lactam rings, therefore Penicillin-Binding Protein (PBPs) cannot occur and cell wall synthesis can continue, but if the bacteria have the additional ability to hydrolyze Cefotaxime and Ceftazidime's $\beta$-lactam ring, this is called Extended-spectrum $\beta$-lactamase (ESBL). ${ }^{13}$ Thus, it can be seen that gram-positive bacteria have already become ESBL. Amoxicillin is one of the Penicillin Extended-Spectrum groups which has greater activity than Penicillin against gram-negative bacteria because there is an increased ability to penetrate the outer membrane of gram-negative bacteria. Nevertheless, similar to Penicillin, Amoxicillin is also activated by many $\beta$-lactamases, therefore, they have high antibiotic resistance. Ceftriaxone, Cefotaxime, and Ceftazidime include the third class of Cephalosporin which have lower activity against grampositive cocci bacteria except for Staphylococcus pneumoniae, while in this study high resistance was in coccus gram-positive bacteria. ${ }^{13}, 31$ Ceftriaxone and Cefotaxime are the most active Cephalosporin for Penicillin-resistant Pneumococcus and are recommended as serious infectious empirical therapies, thus they can be used as empirical sepsis therapy with unknown causes. ${ }^{31}$ In this study, Ceftriaxone and Cefotaxime were 100\% resistant, but only $20 \%$ and $26 \%$ were tested for antibiotic sensitivity, therefore they did not represent all types of samples. Ertapenem is one of the Carbapenem groups that has good activity against many gram-negative, grampositive, and anaerobic stems, and is indicated for infections by bacteria that are already resistant to other antibiotics. ${ }^{13,31}$ This antibiotic is used for the treatment of complicated infections that are not caused by hospital pathogens. ${ }^{13}$ In this study, Ertapenem was $100 \%$ resistant, but only $25 \%$ were tested for antibiotic sensitivity, thus they did not represent all types of samples. Ciprofloxacin is one of the fluoroquinolone class antibiotics that acts as an inhibitor of bacterial DNA formation. This antibiotic is most active in the Fluoroquinolone group against gram-negative bacteria. ${ }^{31}$ It caused high resistance to gram-positive bacteria.

\section{The pattern of antibiotic resistances to gram-negative bacteria in sepsis patients}

The results of this study showed that gram-positive bacteria caused sepsis with $\geq 50 \%$, the 11 antibiotics were Amikacin, Cefoperazone, Piperacillin-Tazobactam, Imipenem, Meropenem, Ertapenem, Fosfomycin, Tobramycin, Gentamycin, Chloramphenicol, and Vancomycin. Meanwhile antibiotics with a resistance level $>50 \%$ were Ampicillin, Ceftriazone, Cefoxitin, Cefazolin, Amoxicillin, Aztreonam, Ampicillin-Sulbactam, Ciprofloxacin, Cefotaxime, TrimethoprimSulfamethoxazole, Cefepime, Tetracyclin, Ceftazidime, Nitrofurantoin, Tigecyclin, and Levofloxacin.

Gram-negative bacteria had a resistance level of $\geq 50 \%$ in Amoxicillin, Tetracyclin, and Ciprofloxacin. ${ }^{32}$ Nevertheless, there are differences in Cefoperazone that has a high level of resistance, while in this study it has a high level of sensitivity.

Overall, the difference in this study with previous studies was because sensitivity tests were performed using different antibiotics, thus the results are different. Not all antibiotic groups were tested, it depended on the type of bacteria they wanted to test. ${ }^{33}$ During sensitivity test, doses of antibiotics used in every study was different, minimum inhibitory concentration (MIC) which is the lowest level of antibiotics that can inhibite the growth and development of bacteria also caused different results in sensitivity test. The pattern of using empirical antibiotic therapy also greatly influenced antibiotic resistance, if the empirical antibiotics used are not appropriate, it will change the pattern of bacteria in the body. Therefore, when the culture and sensitivity tests are performed, it can give different results. The development of bacteria also greatly affected the increase in antibiotic resistance. The development of bacteria in each location varied, because the geographical location of each region was different and this resulted in different environment as well, therefore the level of antibiotic resistance was different. ${ }^{34}$ Pathways of resistance, such as bacteria producing enzymes that damage drugs, changing permeability, modifying structural targets for drugs, modifying metabolic pathways that bypass reactions inhibited by drugs, or modifying enzymes so the drug does not affect it but can still perform its metabolic functions. ${ }^{13}$ Each type of bacteria have different resistance paths, thus the antibiotic resistance is varied. Different sources of bacterial etiology that cause sepsis in 
this study with previous studies led to differences in the level of resistance that occurs in sepsis patients. The difference in comorbidities in sepsis patients will affect the immune response of the patient, therefore the bacterial pattern produced is also different. A history of the use of invasive actions in sepsis patients also affect the differences in the level of antibiotic resistance, especially in gram-positive bacteria. The wisdom of using sepsis therapy in each hospital also differs as a result of the resistance pattern that is also different.

The use of antibiotics is strongly influenced by the spectrum of activity against bacteria. Antibiotics that include broad spectrum in this study were Ampicillin, Amoxicillin, Cefoxitin, Ceftriaxone, Ceftazidime, Cefotaxime, Cefoperazone, Cefepime, Imipenem, Meropenem, Ertapenem, Fosfomycin, Chloramphenicol, Tetracyclin, Tigecyclin, Levofloxacin, Ciprofloxacin, Nitrofurantoin, Ampicillin-Sulbactam, and TrimethoprimSulfamethoxazole. In this study, from 20 antibiotics, there were only 6 antibiotics in which the pathogen were still sensitive, namely Cefoperazone, Imipenem, Meropenem, Ertapenem, Fosfomycin, and Chloramphenicol. In this study, antibiotic that was included in the extended spectrum was Piperacillin-Tazobactam. In this study, PiperacillinTazobactam was still very sensitive, therefore it could still be used primarily in its indications. Meanwhile, the narrow spectrum included in this study were Vancomycin, Aztreonam, Gentamycin, Amikacin, and Tobramycin. In this study, only Aztreonam had a high level of resistance, the other 4 were still sensitive, namely Vancomycin, Gentamycin, Amikacin, and Tobramycin.

In this study, the three most sensitive antibiotics were Cefoperazone, Amikacin, and Piperacillin-Tazobactam. Cefoperazone was included to the third generation Cephalosporin group, which has increased activity against gram-negative rods. ${ }^{13}$ This was what caused the antibiotic to be still sensitive because in this study the most bacteria that caused sepsis was gram-positive. Amikacin is from Aminoglycoside class with working mechanism as an irreversible inhibitor of protein synthesis. This antibiotic is used for gram-negative enteric bacteria, especially if the isolates are drug resistant and if there is suspect sepsis. ${ }^{13}$ This antibiotic is resistant to many enzymes that activate Gentamycin and Tobramycin, thus the bacteria can be resistant to Gentamycin and Tobramycin. ${ }^{31}$ PiperacillinTazobactam is a combination of Piperacillin (betalactamase) with Tazobactam (penicillinase inhibitors). Piperacillin is indicated in the bacterium Pseudomonas, Enterobacter, and some cases in Klebsiella species, therefore more specifically targeted bacteria are killed combined with Tazobactam. Thus, this antibiotic activity is increasing, it makes this antibiotic still very sensitive. ${ }^{31}$

In this study, the three most resistant antibiotics were Cefoxitin, Ceftriaxone, and Ampicillin. These three antibiotics were $\beta$-lactam antibiotics, thus they have a resistance mechanism by producing $\beta$-lactamase which is able to open the $\beta$-lactam ring, therefore PBPs cannot be produced and cell wall synthesis can continue. Cefoxitin is a second class Cephalosporin antibiotic that has a lower mechanism of action on gram-positive but better on gramnegative than the first group Cephalosporin. ${ }^{30}$ It can cause high resistance to cefoxitin in gram-positive bacteria. Ceftriaxone is the third class of Cephalosporin that has lower activity against gram-positive cocci bacteria except for Staphylococcus pneumoniae, while in this study it has high resistance levels. ${ }^{13}$ However, Ceftriaxone is a recommended antibiotic for serious infection empirical therapy, thus it can be used as empirical sepsis therapy for unknown cause. ${ }^{31}$ In this study, Ceftriaxone experienced $89.8 \%$ resistance, but only $20 \%$ perfomed antibiotic sensitivity tests, therefore they did not represent all types of samples. Ampicillin was found more than 50 different $\beta$ lactamases, thus the resistance level increased. ${ }^{13}$

\section{Conclusion}

The most sensitive antibiotics in gram-positive bacteria were Piperacillin-Tazobactam, Daptomycin, and Clindamycin. The sensitive antibiotics in gram-negative bacteria were Amikacin, Cefoperazone, and PiperacillinTazobactam.

\section{CONFLICT OF INTEREST}

The author stated there is no conflict of interest in this study.

\section{REFERENCES}

1. Singer M, Deutschman CS, Seymour CW, et al. The Third International Consensus Definitions for Sepsis and Septic Shock (Sepsis-3). JAMA. 2016; 315: 801-10.

2. Levy MM. Introduction. In: Daniels $R$ and Nutbeam $T$, (eds.). ABC of Sepsis. Chichester: Wiley-Blackwell, 2009, p. 1.

3. Angus DC, Linde-Zwirble WT, Lidicker J, Clermont G, Carcillo $\mathrm{J}$ and Pinsky MR. Epidemiology of Severe Sepsis in the United States: Analysis of Incidence, Outcome, and Associated Costs of Care. Critical Care Medicine. 2001; 29: 1303-10.

4. Nachtigall I, Tamarkin A, Tafelski S, et al. Impact of Adherence to Standard Operating Procedures for Pneumonia on Outcome of Intensive Care Unit Patients*. Critical Care Medicine. 2009; 37: 159-66.

5. Engel C, Brunkhorst FM, Bone HG, et al. Epidemiology of Sepsis in Germany: Results from a National Prospective Multicenter Study. Intensive Care Med. 2007; 33: 606-18.

6. Pradipta IS, Sodik DC, Lestari K, et al. Antibiotic Resistance in Sepsis Patients: Evaluation and Recommendation of Antibiotic Use. North American Journal of Medical Sciences. 2013; 5: 344-52.

7. Suharjo J and Cahyono J. Terapi Antibiotik Empiris pada Pasien Sepsis Berdasarkan Organ Terinfeksi. Dexa Medica. 2007; 20: 85-90.

8. Burgess DS and Abate BJ. Antimicrobial Regimen Selection. In: DiPiro JT, Talbert RL, Yee GC, Matzke GR, Wells BG and Posey LM, (eds.). Pharmacotherapy: $A$ Pathophysiologic Approach. 6th ed. New York: McGrawHill, 2005, p. 1920-1 
9. Garnacho-Montero J, Ortiz-Leyba C, Herrera-Melero I, et al. Mortality and Morbidity Attributable to Inadequate Empirical Antimicrobial Therapy in Patients Admitted to the ICU with Sepsis: A Matched Cohort Study. The Journal of Antimicrobial Chemotherapy. 2008; 61: 436-41.

10. Indonesia KKR. Kemenkes dan Kementan Berkomitmen untuk Kendalikan Resistensi Antimikroba. Jakarta: Kementerian Kesehatan Republik Indonesia, 2016.

11. Viswanathan VK. Off-Label Abuse of Antibiotics by Bacteria. Gut Microbes. 2014; 5: 3-4.

12. Michael CA, Dominey-Howes D and Labbate M. The Antimicrobial Resistance Crisis: Causes, Consequences, and Management. Frontiers in Public Health. 2014; 2: 145-

13. Morse S, Brooks G, Carroll K, Butel J and Mietzner T. Jawetz, Melnick, \& Adelberg's Medical Microbiology, 25th edition. 2010.

14. Cantas L, Shah SQ, Cavaco LM, et al. A Brief MultiDisciplinary Review on Antimicrobial Resistance in Medicine and Its Linkage to the Global Environmental Microbiota. Frontiers in Microbiology. 2013; 4: 96.

15. von Nussbaum F, Brands M, Hinzen B, Weigand S and Häbich D. Antibacterial Natural Products in Medicinal Chemistry--Exodus or Revival? Angewandte Chemie (International ed in English). 2006; 45: 5072-129.

16. Paknikar SS and Narayana S. Newer Antibacterials in Therapy and Clinical Trials. North American Journal of Medical Sciences. 2012; 4: 537-47.

17. Eachempati SR, Hydo L and Barie PS. Gender-Based Differences in Outcome in Patients with Sepsis. Archives of Surgery (Chicago, III : 1960). 1999; 134: 1342-7.

18. Kumalo A, Kassa T, Mariam Z, Daka D and Henok A. Bacterial Profile of Adult Sepsis and Their Antimicrobial Susceptibility Pattern at Jimma University Specialized Hospital, South West Ethiopia. iMedPub Journals. 2016 10: 3 .

19. Martin GS, Mannino DM, Eaton S and Moss M. The Epidemiology of Sepsis in the United States from 1979 through 2000. The New England Journal of Medicine. 2003; 348: 1546-54.

20. Finfer S, Bellomo R, Lipman J, French C, Dobb G and Myburgh J. Adult-Population Incidence of Severe Sepsis in Australian and New Zealand Intensive Care Units. Intensive Care Med. 2004; 30: 589-96.

21. Ngonzi J, Bebell LM, Fajardo Y, et al. Incidence of Postpartum Infection, Outcomes and Associated Risk Factors at Mbarara Regional Referral Hospital in Uganda. BMC Pregnancy and Childbirth. 2018; 18: 270.
22. Carbajal-Guerrero J, Cayuela-Domínguez A, Fernández-García $\mathrm{E}$, et al. [Epidemiology and Long-Term Outcome of Sepsis in Elderly Patients]. Medicina Intensiva. 2014; 38: 21-32.

23. Mayr FB, Yende S, Linde-Zwirble WT, et al. Infection Rate and Acute Organ Dysfunction Risk as Explanations for Racial Differences in Severe Sepsis. JAMA. 2010; 303: 2495-503.

24. Martin GS, Mannino DM and Moss M. The Effect of Age on the Development and Outcome of Adult Sepsis. Critical Care Medicine. 2006; 34: 15-21.

25. Angus DC and Van der Poll T. Severe Sepsis and Septic Shock. The New England journal of medicine. 2013; 369: 840-51.

26. Kang-Birken SL and DiPiro JT. Sepsis and Septic Shock. In: DiPiro JT, Talbert RL, Yee GC, Matzke GR, Wells BG and Posey LM, (eds.). Pharmacotherapy: A Pathophysiologic Approach. 6th ed. New York: McGrawHill, 2005, p. 2137

27. Alberti C, Brun-Buisson $\mathrm{C}$, Burchardi $\mathrm{H}$, et al. Epidemiology of Sepsis and Infection in ICU Patients from an International Multicentre Cohort Study. Intensive Care Med. 2002; 28: 108-21.

28. Mayr FB, Yende S and Angus DC. Epidemiology of Severe Sepsis. Virulence. 2014; 5: 4-11.

29. Karimzadeh I, Mirzaee M, Sadeghimanesh N and Sagheb MM. Antimicrobial Resistance Pattern of GramPositive Bacteria during Three Consecutive Years at the Nephrology Ward of a Tertiary Referral Hospital in Shiraz, Southwest Iran. Journal of Research in Pharmacy Practice. 2016; 5: 238-47.

30. Trevor A, Katzung B, Masters S and Knuidering-Hall M. Katzung \& Trevor's Pharmacology Examination and Board Review, 10th Edition. McGraw-Hill Education, 2012.

31. Katzung BG, Masters SB and Trevor AJ. Basic \& Clinical Pharmacology. New York; London: McGraw-Hill Medical ; McGraw-Hill [distributor], 2012.

32. Guevara N, Guzmán M, Merentes A, et al. Patrones de susceptibilidad antimicrobiana de bacterias gramnegativas aisladas de infecciones del tracto urinario en Venezuela: Resultados del estudio SMART 2009-2012. Revista chilena de infectología. 2015; 32: 639-48.

33. Forbes BA, Sahm DF, Weissfeld AS and Bailey WR. Bailey \& Scott's Diagnostic Microbiology. St. Louis, Mo.: Elsevier Mosby, 2007.

34. Llewelyn MJ and Cohen J. Tracking the Microbes in Sepsis: Advancements in Treatment Bring Challenges for Microbial Epidemiology. Clinical Infectious Diseases. 2007; 44: $1343-8$. 